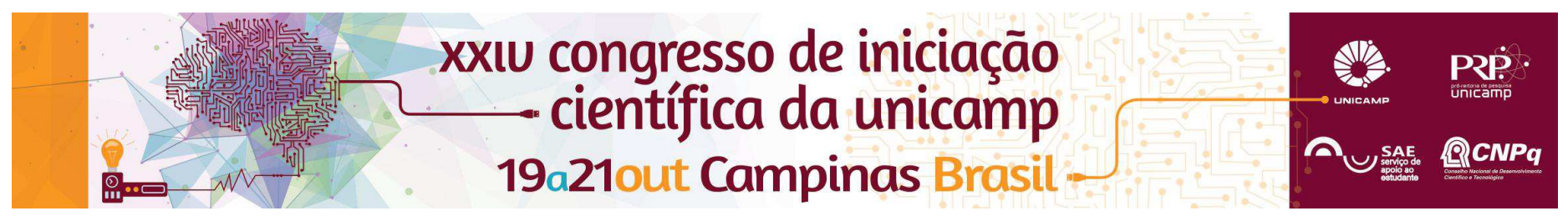

\title{
STUDENTS LEARNING TECHNOLOGY CONCEPTS BY CONSTRUCTION OF A DEVICE
}

\section{Luana M. Siqueira*, Conrado L. Silva*(Graduation Students); João V.V. D’Abreu.}

\begin{abstract}
The project seeks to explore the high school students interest in robotics, and the learning in technology basic concepts, by building a mechanism with undergraduation students orientation. To produce the device, the young people could have contact with: the mechanics, in the construction of the propeller and its coupling the engine; electronics, to find feed alternatives for the components, and the connection of the LEDs to the UNO Arduino; computing, to learn basics of $\mathrm{C}++$ language.
\end{abstract}

Key words: Technological learning, arduino, air display.

\section{Introduction}

The advice treat of a propeller-circuit with a led's line that, with the movement around an axis, eludes the projection of a figure (or whatever is desire). This should be from assembling of characters by the mechanical scanning. The phenomenon called the persistence of vision and its psychological partner, the phi phenomenon-the mental bridge that the mind forms to conceptually complete the gaps between the frames or pictures. Persistence of vision also plays a role in keeping the world from going pitch black every time blinks the eyes, theoretically because the eyes can't separate events that in a shorter time interval than $1 / 10$ of a second.

\section{Results and Discussion}

The device done is constituted from a propeller coupling to axis of engine, were fixed eleven led's and one UNO Arduino. (Image 1)

Using the mechanical scanning principles, the led's are pre-programmed for, in moments pre established, blink, so through the programming and the propeller's revolution, it was possible cause to observers the image via illusion optical.

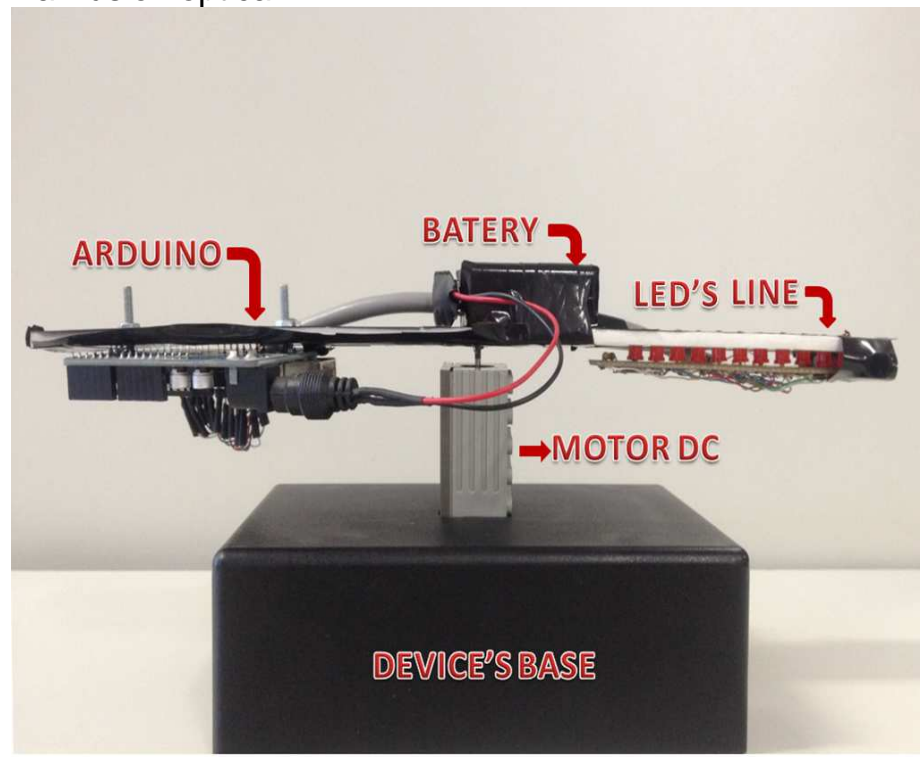

Figure 1. The device

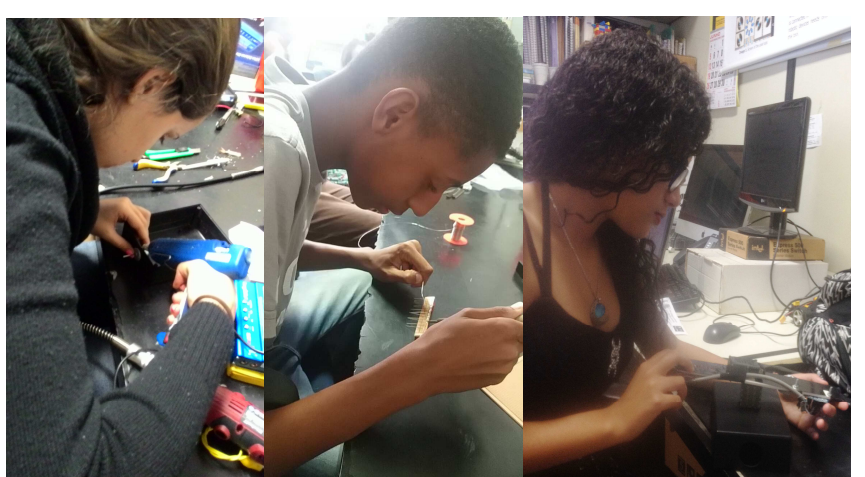

Figure 2. Students building

\section{Conclusions}

In this project it was possible notice that, to period's final, the students were interested in the explored areas and more eager to learn more. Although difficulties, they knew deal with adversities and complications to long of project, became more careful and perceptible to future errors, opening horizons in relation to engineering knowledge.

\section{Acknowledgement}

We acknowledge the importance of NIED (NÚCLEO DE INFORMÁTICA APLICADA A EDUCAÇÃO) by space and tools available, accountable for the project fruition. And too, $\mathrm{PRP} / \mathrm{UNICAMP/CNPq}$ which became this work has been made possible by sponsorship.

${ }^{1}$ http://www.instructables.com/id/persistence-of-vision-display-POV/. ${ }^{2}$ http://professormarlonnardi.blogspot.com.br/p/participe-construcaopropp.html

${ }^{3}$ https://www.arduino.cc/ 